\title{
A perspectiva da qualidade da educação presente nas ações do Conselho Municipal de Educação de Rio Verde - GO
}

The perspective of quality of education present in actions of the Municipal Council of Education of Rio Verde - GO

La perspectiva de la calidad de la educación presente en las acciones del Consejo Municipal de Educacion de la ciudad de Rio Verde-GO

\section{Elizabeth Gottschalg Raimann, Renata Freitas Dias*}

\section{Resumo}

O artigo objetiva apresentar os resultados de pesquisa, na qual se buscou analisar a perspectiva da qualidade da educação presente nas ações do Conselho Municipal de Educação de Rio Verde/GO (COMERV). Para isso, fez-se uma pesquisa exploratória e documental em atas, resoluções e legislação vigente do COMERV, entre os anos de 1997 a 2016. A análise foi subsidiada pelas contribuições de Bordignon (2009), Lima (2001, 2010) e Motta (1984). As categorias de análise foram: qualidade, autonomia e participação. Como resultados, as ações do Conselho 
apontam para possibilidades de se buscar a qualidade da educação mediante ações de inclusão, melhoria no atendimento aos alunos e revisão no atual sistema de eleição de seus participantes. Sobre as normas atuais relacionadas à eleição dos membros do Conselho, foi possível concluir que a escolha pelo chefe do Poder Executivo, a partir de lista tríplice apresentada pela comunidade, tem comprometido a ação democrática e a qualidade da educação. A boa vontade e conhecimento dos conselheiros não bastam para romper o paradigma da participação limitada, tendo em vista, principalmente, que os conselhos municipais de educação têm o desafio de trabalhar a sua função mobilizadora e propositiva junto à sociedade, posicionando-se contra as situações que impossibilitem a qualidade social da educação.

Palavras-chave: Conselho Municipal de Educação. Qualidade da educação. Autonomia. Participação.

\section{Abstract}

The aim of this article is to present the results of a research that sought to analyze the perspective of the quality of education present in actions of the Municipal Council of Education of Rio Verde / GO (COMERV). To accomplish this, an exploratory and documentary research was made of the minutes, resolutions and current legislation of COMERV, between the years of 1997 to 2016. The analysis was substantiated by the contributions of Bordignon (2009), Lima (2001, 2010) and Motta (1984). The categories of analysis were: quality, autonomy and participation. The results demonstrate that the Board's actions point to possibilities in seeking the quality of education through inclusion actions, improvement in assistance to students and a revision in the current election system of its participants. Regarding the current rules related to the election of Council members, it was possible to conclude that the choice made by the head of the Executive Power, based on a triple list presented by the community, has compromised democratic action and the quality of education. The counselors' goodwill and knowledge are not enough to break the paradigm of limited participation, especially in view of the fact that municipal councils of education have the challenge of working the mobilizing and purposeful function with society, positioning themselves against situations that make the social quality of education impossible.

Keywords: Municipal Council of Education. Quality of education. Participation. Autonomy. 


\section{Resumen}

Este artículo tiene como objetivo presentar los resultados de investigación, en la cual se buscó analizar la perspectiva de la calidad de la educación presente en las acciones del Consejo Municipal de Educación en la ciudad de Río Verde/GO (COMERV). Para eso, se realizó una investigación exploratoria y documental en actas, resoluciones y legislación vigente del COMERV, entre los años 1997 a 2016. El análisis fue subsidiado por las contribuciones de Bordignon (2009), Lima (2001, 2010) y Motta (1984). Las categorías de análisis fueron: calidad, autonomía y participación. Como resultados, las acciones del Consejo apuntan a posibilidades de buscarse la calidad de la educación mediante acciones de inclusión, mejora en el atendimiento a los alumnos y revisión en el actual sistema de elección de sus participantes. Sobre las normas actuales relacionadas con la elección de los miembros del Consejo, fue posible concluir que la elección por el jefe del Poder Ejecutivo, a partir de una lista triple presentada por la comunidad, ha comprometido la acción democrática y la calidad de la educación. La buena voluntad y conocimiento de los consejeros no bastan para romper el paradigma de la participación limitada, teniendo en vista, principalmente, que los consejos municipales de educación tienen el desafío de trabajar su función movilizadora y propositiva junto a la sociedad, posicionándose contra las situaciones que imposibiliten la calidad social de la educación.

Palabras clave: Consejo Municipal de Educación. Calidad de la educación. Participación. Autonomía.

\section{Introdução}

A discussão sobre ações desenvolvidas por conselhos municipais de educação ganha relevância na medida em que esse órgão pretende ser um espaço que possibilita a participação de diferentes setores da comunidade local, numa perspectiva de gestão democrática. Com o processo de elaboração, aprovação e implementação dos Planos Municipais de Educação, a partir do Plano Nacional de Educação (2014-2024), os 
conselhos passam a ser atores fundamentais. Nesse contexto, esta pesquisa se justifica pelo papel que os conselhos municipais de educação podem desempenhar junto a outros órgãos municipais, além das funções, que lhe são inerentes, de regular e deliberar sobre a educação municipal e, principalmente, de desenvolver ações em prol da qualidade social e política da educação.

Parte-se da concepção de que esse tipo de conselho pode possibilitar a participação democrática, podendo contribuir, num cenário de gestão antiautoritária, na elaboração e acompanhamento das políticas públicas educacionais locais.

Para Lima (2001), conselhos municipais de educação são conquistas que merecem ser destacadas como ação democrática e de transformação social, desde que a participação seja, de fato, efetiva. Por outro lado, nem sempre se tem esse entendimento, pois esse tipo de conselho é um órgão governamental, instituído pelo poder executivo. É possível, portanto, que os próprios conselheiros tenham dificuldades em compreender que estão ali em nome da população e que anseios da sociedade devem ser respeitados.

A educação brasileira é afetada pelo descaso dos governantes na implantação de políticas públicas que atendam aos direitos sociais com igualdade de condições, justiça isonômica e uma legislação com aplicabilidades reais. Dessa forma, para se conceituar qualidade da educação, é preciso considerar que existem projetos de educação marcados pela disputa de classes. De um lado, para a sociedade liberal, a qualidade está relacionada diretamente ao atendimento do mercado. Para a classe trabalhadora, por outro lado, significa valor social voltado para a cidadania plena.

Nesse cenário, o problema norteador desta pesquisa foi conhecer e analisar a perspectiva da qualidade de educação presente nas ações do Conselho Municipal de Educação de Rio Verde/GO (COMERV).

O Conselho Municipal de Educação de Rio Verde, doravante COMERV, foi criado pela Lei 3.496, de 14 de maio de 1997 (RIO VERDE, 1997a), alterada pela Lei 3.544, de 11 de agosto de 1997 (RIO VERDE, 1997b), nos termos do Art. 186 e seguintes da Lei Orgânica do Município 
e da Lei de Criação do Sistema Municipal de Ensino — Lei 3.494/1997, como "órgão normativo, consultivo, deliberativo, supervisor e fiscalizador de natureza educacional, tendo como finalidade precípua velar pela organização e pelo funcionamento eficaz do Sistema Municipal de Ensino, em consonância com a legislação superior", de acordo com as informações disponibilizadas na página do Conselho.

Estão sob a atuação do COMERV todas as Unidades Escolares da Rede Pública Municipal e as Unidades Escolares de Educação Infantil da Rede Privada do município de Rio Verde/GO. O Conselho é composto por 15 conselheiros, escolhidos em lista tríplice, para mandato de quatro anos, sendo professores, especialistas em educação, representantes de entidades ligadas à educação e de segmentos organizados da sociedade.

Ainda segundo as informações disponibilizadas na página do Conselho, o colegiado funciona de forma ininterrupta desde o ano de 1997, em espaço próprio cedido pela Secretaria Municipal de Educação, com expediente diário e sessões ordinárias regulares.

Com o objetivo de trazer os resultados da pesquisa, será apresentado, inicialmente, o caminho investigativo. Na sequência, serão trazidas à tona a discussão em torno da qualidade da educação e a análise dos dados levantados. Por fim, algumas considerações sobre a atuação do COMERV em prol da qualidade da educação.

\section{O caminho da pesquisa}

O caminho investigativo buscou compreender como a perspectiva de qualidade da educação foi se construindo ao longo das últimas décadas, a partir da reforma da educação brasileira. Para isso, inicialmente, procurou-se identificar, nos documentos oficiais, os discursos sobre qualidade da educação no Brasil e analisar as ações do COMERV voltadas para a obtenção dessa tão almejada qualidade. A análise documental foi primordial para se alcançar o objetivo aqui proposto, pois é a partir da 
compreensão do processo histórico que se pode entender a construção da identidade do COMERV.

Com essa finalidade, analisaram-se os documentos produzidos pelo COMERV entre 1997 a 2016, procurando-se direcionar o olhar analítico, principalmente para a composição e a função do conselho, a partir das seguintes categorias de análise: qualidade da educação, autonomia e participação, a partir das contribuições do materialismo histórico dialético.

O acesso ao acervo documental quanto à institucionalização e à regulamentação do COMERV necessitou ser precedido de contato formal com o presidente do Conselho, para esclarecimentos relacionados ao teor da pesquisa e à sua relevância social e acadêmica.

A análise dos documentos permitiu encontrar informações sobre a estrutura e funcionamento do COMERV, a regulamentação da escolha dos representantes, bem como sua dinâmica de tomada de decisão, a qual pretende direcionar os indicativos de conceito de qualidade propostos por esse município. Os documentos mostram a concepção do Conselho sobre educação e sua forma de atuação frente à realidade educacional.

Os documentos que constituíram o corpus da pesquisa são leis e outros documentos oficiais que institucionalizam o Sistema Municipal de Ensino de Rio Verde e o Conselho Municipal de Educação como órgão do Sistema Municipal de Ensino. São, portanto, a legislação que regulamenta a criação e o funcionamento do COMERV. Desse acervo, fazem parte, dentre outros documentos, as atas de reuniões (1997-2016); o regimento interno do Conselho; resoluções e normatizações expedidas pelo COMERV entre 1997 e 2016. A análise do arquivo de dezenove anos de existência do conselho revelou a existência de, aproximadamente, 456 atas, 402 resoluções e 32 decretos. Desse universo, foram selecionadas 13 atas e 13 legislações, dentre elas o regimento interno, lei de criação do Conselho, algumas resoluções, tendo como parâmetro para a escolha as categorias de análise elegidas para esta pesquisa: qualidade da educação, autonomia e participação. A análise do conteúdo se justifica neste estudo, pois, ao relacionar dialeticamente o contexto histórico com realidade concreta, permite ao pesquisador questionar o objeto investigado, desvelando-o para 
além da aparência. Para Gamboa (2007, p. 173), "o enfoque crítico-dialético busca apreender o fenômeno em seu devir histórico e em suas interrelações com outros fenômenos buscando compreender os processos de sua transformação, suas contradições e potencialidades de mudanças".

A análise crítica do conteúdo permite evidenciar as tensões e contradições existentes nas ações do Conselho, ao buscar a participação da sociedade nas decisões das políticas públicas, tentando dar voz aos diversos segmentos que compõem o Conselho.

\section{A qualidade da educação}

A qualidade da educação é uma temática debatida há décadas, tanto pelos organismos internacionais quanto pelos órgãos do governo e da sociedade civil, pois é considerado um objeto de disputa na sociedade capitalista. Nesse sentido, a qualidade da educação faz parte de projetos educacionais em conflito. Entre as classes sociais existentes, o tema suscita conotações diferentes, pois é necessário observar que tipo de qualidade se está almejando, seja por parte da classe trabalhadora, seja pela classe dirigente.

Importante destacar que, a cada década, o conceito foi sofrendo mudanças influenciadas por questões políticas, sociais e econômicas, o que provocou a elaboração de documentos oficiais tanto por parte dos organismos internacionais quanto pelo governo nacional e da sociedade civil. A mobilização em torno da educação, nos finais dos anos de 1980 para 1990, resultou no documento elaborado na Conferência de Educação para Todos, em Jomtien, na Tailândia, em 1990. No inicio da década de 2000, ocorreu o Fórum de Educação para Todos, em Dakar, no Senegal. Nesses dois eventos, a qualidade da educação foi colocada em evidência, tomada como uma das metas a serem alcançadas pelos países signatários dessas declarações. O Brasil, como participante, formalizou adesão a esses acordos e, a partir daí, procurou adequar sua política educacional às 
orientações internacionais, buscando alinhar a educação ao desenvolvimento sustentável, dentro dos objetivos da economia mundial.

Nos governos de Fernando Henrique Cardoso e de Luís Inácio Lula da Silva, a qualidade da educação foi um ponto de pauta da agenda educacional. Os documentos, aparentemente, apontavam para uma atuação propositiva do governo. Porém, na essência, percebe-se que suas políticas não correspondiam aos anseios da sociedade, em especial para a classe trabalhadora. Isso se constata pelo modo com o qual o governo analisa a qualidade educacional, ou seja, utilizando parâmetros quantitativos, índices para aferir a qualidade educacional, como o Índice de Desenvolvimento da Educação Básica (IDEB).

A partir do final da década de 2000, intensificou-se a mobilização da sociedade civil, especialmente de entidades e associações educacionais, em torno da CONAE (Conferência Nacional da Educação). O documento de referência elaborado nesse encontro aponta para a qualidade socialmente referenciada (CONAE, 2015). Essa proposição é incorporada aos documentos oficiais, principalmente no Plano Nacional de Educação (2014-2024).

O conceito de qualidade da educação como construção histórica, que assume diferentes significados em tempos e espaços diversos, e tem relação com os lugares de onde falam os sujeitos, os grupos sociais a que pertencem, os interesses e os valores envolvidos, se expressam nas Diretrizes Curriculares Nacionais para a Educação Básica:

Outro conceito de qualidade passa, entretanto, a ser gestado por movimentos de renovação pedagógica, movimentos sociais, de profissionais, e por grupos políticos: o da qualidade social da educação. Ela está associada às mobilizações pelo direito à educação, à exigência de participação e de democratização e comprometida com a superação das desigualdades e justiças (BRASIL, 2013, p. 107).

$\mathrm{Na}$ aparência da lei, a qualidade da educação busca atender às demandas sociais, porém, na essência, observando-se a situação real 
brasileira, percebe-se que a qualidade é aferida com parâmetros meramente quantitativos.

Em sua análise, Lima (2014) afirma que a concepção de qualidade não deveria ser expressa por resultados quantitativos. Essa forma de avaliar a qualidade vincula-se a uma concepção mínima de qualidade da educação básica escolar, que é contrária à concepção de qualidade vinculada ao objetivo de formação de cidadão, estabelecido na legislação brasileira.

O quadro abaixo sintetiza as concepções de qualidade da educação a partir da década de 1980 até os dias atuais:

Quadro 1 - A qualidade da educação nas últimas décadas

\begin{tabular}{|c|c|c|}
\hline PERÍODO & QUANTIDADE & QUALIDADE \\
\hline 1980-1990 & Índice de matrícula & $\begin{array}{l}\text { Acesso: Garantir o acesso à educação foi o marco } \\
\text { da qualidade desse período de universalização do } \\
\text { ensino. }\end{array}$ \\
\hline $1990-2000$ & $\begin{array}{l}\text { Índice de repetência, } \\
\text { evasão e abandono. }\end{array}$ & $\begin{array}{l}\text { Permanência: Garantir a permanência do aluno na } \\
\text { escola, o acesso já não era suficiente para garantir } \\
\text { a qualidade. }\end{array}$ \\
\hline 2000- 2007 & $\begin{array}{l}\text { Indicadores de eficiência } \\
\text { e qualidade - SAEB }\end{array}$ & $\begin{array}{l}\text { Equidade e eficiência: o acesso, a permanência e } \\
\text { o direito a educação para todos. A qualidade teria } \\
\text { indicadores mediante a avaliação em larga escala. }\end{array}$ \\
\hline 2007- 2018 & $\begin{array}{l}\text { Indicadores de eficiência } \\
\text { e qualidade - IDEB }\end{array}$ & $\begin{array}{l}\text { Para além do acesso e permanência existe a } \\
\text { preocupação com o sucesso escolar. Para a } \\
\text { qualidade da educação permanecem indicadores } \\
\text { aferidos por avaliações em larga escala. } \\
\text { Com o movimento da CONAE (2015) é incorporada a } \\
\text { proposta de qualidade socialmente referenciada. }\end{array}$ \\
\hline
\end{tabular}

Fonte: elaboração das autoras (CASTRO; CARNOY, 1997; CASTRO, 1999; BRASIL, 2004, HADDAD, 2008, CONAE, 2015).

O quadro pretende mostrar os diferentes enfoques pelos quais passou a concepção de qualidade da educação desde 1980. Percebe-se nas propostas governamentais a incorporação de índices e parâmetros para aferir a qualidade educacional. Com o Plano de Desenvolvimento da Educação (PDE), o Sistema de Avaliação da Educação Básica - SAEB é reformulado e o Índice de Desenvolvimento da educação Básica (IDEB) é incorporado mediante ampliação de outras avaliações em larga escala, 
como Prova Brasil, Avaliação Nacional de Alfabetização (ANA) e Provinha Brasil. Por outro lado, os movimentos sociais e entidades educacionais, durante as discussões em torno da Conferência Nacional da Educação (CONAE) e a formulação do documento referência deixam claro a perspectiva de qualidade da educação referenciada no social, como se lê:

A 'educação de qualidade' é aquela que contribui com a formação dos estudantes nos aspectos humanos, sociais, culturais, filosóficos, científicos, históricos, antropológicos, afetivos, econômicos, ambientais e políticos, para o desempenho de seu papel de cidadão no mundo, tornandose, assim, uma qualidade referenciada no social (CONAE, 2015, p. 64).

O mesmo documento, ao tratar dos parâmetros de avaliação da qualidade da educação socialmente referenciada, se expressa contrário aos índices quantitativos que levam apenas a classificação das instituições. Afirma:

[...] uma política nacional de avaliação voltada para a qualidade da educação, para a democratização do acesso, da permanência, da participação e da aprendizagem deve ser entendida como processo contínuo que contribua para o desenvolvimento dos sistemas de ensino, como expressão do SNE, excluindo qualquer forma de 'ranqueamento' e classificação das escolas e instituições educativas - tanto as públicas, quanto as privadas. Desta forma, a política nacional de avaliação levará em consideração, na sua estrutura, fatores intra e extraescolares como parâmetros avaliativos, tendo em vista as desigualdades educacionais ainda existentes no território nacional (CONAE, 2015, p. 68).

A qualidade da educação, até chegar à qualidade social, foi objeto de luta da sociedade e as forças econômicas, para não perderem o controle, utilizaram discursos alienantes de qualidade nos documentos da educação, ao afirmar que suas ações se pautavam na democracia. É o que se observa, por exemplo, no último período retratado no quadro, em que os discursos apontam sempre para a participação da sociedade, mas se sabe que, na verdade, essa participação é sempre muito limitada. 
Vale ressaltar que, na proposta do CONAE (2015), a política educacional deve ser considerada como um desafio à educação municipal, que, por sua vez, deve contar com o apoio da sociedade para a participação do processo democrático pensado numa educação de qualidade socialmente referenciada. Porém, o contexto não favorece para que se tenha uma educação de qualidade social, tendo em vista que a proposta do sistema é uma educação pautada na produtividade e na eficiência, balizada por índices.

\section{A atuação do Conselho Municipal de Educação de Rio Verde/GO e a qualidade da educação}

Os conselhos municipais de educação (CME), por serem instituições corresponsáveis por garantir o direito à qualidade educacional, devem pautar suas ações na necessidade social local, evitando atender à necessidade do governo. Como órgão mediador, deveria discutir as políticas públicas educacionais locais com imparcialidade, garantindo sua posição de representante da sociedade civil. Nesse sentido, esses conselhos deveriam propiciar uma participação efetiva e autêntica de seus conselheiros, visando qualidade social na educação.

Como já ressaltado, a criação de conselhos municipais de educação merece destaque como ação democrática e de transformação social. No entanto, nem sempre os conselheiros compreendem que devem representar e defender os interesses da sociedade e não do governo. $\mathrm{Na}$ sociedade como um todo, infelizmente, também prevalece a ideia de que esses conselhos são órgãos governamentais e que, portanto, devem se submeter aos ditames do governo federal. Na análise de Lima (2001, p. 13), os conselhos ainda carecem de vínculo explícito com a sociedade civil organizada, como se vê no excerto a seguir,

São indiscutíveis os avanços que os Conselhos representam, principalmente dentro da conjuntura de exclusão social e do enaltecimento da democracia representativa. Porém, não podemos ser ingênuos a ponto 
de acreditar que os Conselhos representam uma transformação radical da educação e da sociedade. Avançam, sim, em relação à possibilidade da transparência, das informações e da contestação das decisões do Executivo, porém, sem vínculo explícito com a sociedade civil organizada, com os movimentos sociais, com as escolas, os Conselhos podem apenas referendar e assumir o seu papel na pseudoparticipação.

Vê-se, portanto, que avaliar a autonomia de um conselho municipal de educação é questão fundamental na análise de sua atuação. No caso do COMERV, objeto desta investigação, observando sua lei de criação e as que lhe sucederam para alterá-la, pode-se observar que a motivação da lei 3.496/1997 foi a revogação do Art. 6º a qual previa que a autonomia do COMERV seria "assegurada por sua individualização no orçamento municipal e por sua vinculação direta ao prefeito municipal”. Ou seja, o COMERV não possui orçamento próprio e esse é um aspecto importante em relação à autonomia desse órgão.

Outro aspecto que se relaciona diretamente à autonomia referese à forma como os membros do conselho são escolhidos. Na mesma Lei de criação (3.496/1997), o Art. $5^{\circ}$ prevê que "a nomeação dos membros do COMERV dependerá de prévia aprovação do poder Legislativo e será feita pelo chefe do Poder Executivo" (RIO VERDE, 1997a). Essa redação demonstra que a Lei de criação segue os ideários políticos correspondentes à sua época e a participação no viés democrático popular é limitada e fere a participação social como um ato de gestão democrática.

A forma como o COMERV foi instituído interfere na capacidade de autonomia do órgão. Ainda que se reconheça que o Sistema Municipal de Educação e os conselhos municipais de educação são órgãos parceiros e interligados, não se pode admitir a falta de autonomia que impede que os desejos da sociedade sejam ouvidos.

A composição do colegiado do COMERV também contribui negativamente para a participação da sociedade, como explicitaremos a seguir. Motta (1984) propõe diferentes tipos de participação: conflitual, funcional e administrativa. A participação conflitual, para esse autor, é "aquela que se desenvolveu como oposição ao taylorismo. Baseia-se no processo de 
negociação coletiva entre patronato e sindicato de trabalhadores (p. 92)". O autor adverte que essa participação não prosperou no aspecto dos resultados que vigora nos países desenvolvidos. A participação funcional refere-se à prática de reuniões periódicas entre patrões e trabalhadores, entre administradores, funcionários e trabalhadores, entre unidades organizacionais e entre níveis hierárquicos em geral. E a participação funcional envolve todos os interessados e estabelece periodicidade nas reuniões, elementos esses importantes na discussão dos objetivos em comum, sugerindo assim uma democracia popular. A participação administrativa é a mais usual, pois "é um tipo especial de participação, que se organiza por representação [...] formação de comissões [...] que reúnem [...] administradores, funcionários e trabalhadores" (MOTTA, 1984, p. 92).

Dentre os modelos de participação propostos por Motta, a participação administrativa é a que mais se assemelha com o critério de composição do COMERV, que elege seus representantes por categoria de representatividade.

A representatividade dos conselhos municipais de educação é o que traduz a essência da participação do colegiado que, por sua vez, dá indícios para se avaliar a qualidade da educação. Desta forma, é importante conhecer os representantes do COMERV e a forma como ocorre essa representatividade. $\mathrm{Na}$ análise de dois decretos do COMERV referentes a essa temática, respectivamente o de $n^{\circ} 593 / 2009$ e o de $n^{\circ} 847 / 2014$, pode-se perceber que houve uma mudança qualitativa no processo de representatividade, já que o segundo decreto apresenta a forma de organização e a quantidade de indicação por categoria, incluindo representantes do poder público e representantes da rede privada. Se, por um lado, o decreto $n^{\circ} 847 / 2014$ resultou em um salto qualitativo, por nomear as categorias para essa composição, dando uma sensação de maior transparência quanto à escolha dos candidatos; por outro, o número de conselheiros para a composição do COMERV não apresenta a paridade que deve existir no processo democrático de representação social. Do total de 15 vagas, duas representam o governo, sendo uma da Secretária Municipal de Educação e outra da Secretaria Estadual de Educação; oito são divididas entre representantes de escolas municipais, sindicato, instituições federal e municipal e cinco do 
setor privado. Não há representação da população, como pais ou alunos. A desproporcionalidade na distribuição das vagas deixa o processo participativo limitado e a população perde a oportunidade de ter voz no colegiado.

Art. 34 - Os membros do Conselho Municipal de Educação são indicados pela Comunidade em lista tríplice, através dos representantes de classes, ao Chefe do Poder Executivo, que os nomeará nos termos da lei, assegurada as seguintes representações:

I. Dois terços de Representantes do Poder público

a) 1(um) da Secretaria Municipal de Educação;

b) 1(um) da Secretaria Estadual de Educação (Subsecretaria);

c) 1(um) do Sindicato dos Professores da Rede Pública Municipal;

d) 1(um) de Diretores do Ensino Fundamental da Rede Pública Municipal;

e) 1(um) de Diretores da Educação Infantil da Rede Pública Municipal;

f) 1(um) de Diretores das Unidades Escolares do Ensino Rural;

g) 2(dois) de Professores da Rede Pública Municipal;

h) 1(um) da UNIRV- Universidade de Rio Verde;

i) 1(um) da Educação Profissional Pública-IF-Go;

II. Um terço de Representante da Rede Privada

a) 1(um) de diretor da Rede Privada;

b) 1(um) de Professores da Rede Privada;

c) 1(um) da Instrução de Educação Especial;

d) 1(um) da Escola de Pais do Brasil, unidade Rio Verde;

e) 1(um) do Ensino Superior Privado de Ensino Regular ou EAD.

f) (RIO VERDE, 2014, p. 21, grifo das autoras).

Alguns autores nos auxiliam a compreender que o COMERV ainda tem muita dificuldade em construir uma gestão democrática. Cury (2011) afirma que a nova significação do Estado, na concepção da gestão democrática, ocorre na medida em que uma nova configuração da estruturação do conselho é tomada, como, por exemplo, a qualidade da paridade na composição dos membros do CME enquanto órgão gestor das 
políticas sociais, não sendo possível privilegiar mais uma categoria do que outra no número de vagas para a composição do Conselho.

Para Bordignon (2009), mesmo que os conselhos municipais de educação possuam variadas indicações por seguimento de categoria, devese observar de onde essas pessoas falam, quais interesses elas defendem, como por exemplo: um professor modulado dentro da Secretaria Municipal de Educação (SME) não irá falar como professor e sim como membro da SME e, da mesma forma, um professor representando a categoria de pais, não conseguirá se desvencilhar da profissão professor e falar como pai.

Teixeira (2004) afirma que, apesar de a representatividade por categoria ser melhor que a indicação direta pelo chefe do executivo, para inibir escolhas motivadas por interesses pessoais ou mercantis, pode ser que essa representação se torne cooperativa na defesa de interesse do grupo ao qual pertence.

Por sua vez, Alves (2011, p. 46) assinala que, dentre vários fatores, a falta de paridade aponta para o retrocesso na história dos conselhos municipais de educação.

A literatura aponta várias dificuldades no processo de institucionalização dos conselhos como a fragilidade institucional e legal; a desvalorização da cultura de participação social; a falta de autonomia; falta de paridade entre sociedade civil e governo na composição do órgão; baixa representatividade e consequente crise de legitimidade das deliberações.

O formato da composição COMERV remete ao que Lima (2010) chama de participacionismo, que ocorre, segundo a autora quando a participação não é efetiva, resultando numa participação limitada. A participação da sociedade civil deveria ser aumentada, prevendo a participação de país, estudantes e outras associações comunitárias. Alves (2011) afirma que a falta de proporcionalidade da representação no conselho acaba reforçando o poder do Estado. Também, deve-se lembrar de que toda categoria tem seus preteridos, o que dificulta a escolha dentro da própria categoria. Nesses moldes, o princípio democrático sofre mitigação e a sociedade perde a oportunidade de escolher seus representantes. 
A composição dos conselhos, em seu processo de autonomia, indica que a representatividade da pluralidade social pode significar a diversidade das categorias existentes no município e gerar o equilíbrio (BORDIGNON, 2009). Porém, é importante levar em consideração que o conselho de educação de um determinado município não terá uma atuação semelhante a do outro, levando em consideração o fato de que cada conselho possui sua singularidade, particularidade e sua identidade (LIMA, 2010).

Para analisar as ações do COMERV em prol da qualidade da educação, a pesquisa levantou as resoluções emitidas pelo conselho no período de 1997 a 2016.

Contabilizou-se, nesse período, 402 resoluções, cujos conteúdos foram agrupados por temas: aproximadamente $46 \%$ das resoluções dizem respeito à autorização e à regularização de unidades escolares; $25 \%$ estão relacionadas com a aprovação de matrizes curriculares e regimento escolar; $13 \%$ estabelecem normas e diretrizes pedagógicas e também administrativas acerca do sistema municipal de ensino; $14 \%$ das resoluções objetivam solucionar pendências de alunos específicos (ausência de histórico escolar ou autorização para cursar determinada série, apesar da idade, por exemplo); 3\% das resoluções relacionam-se à aprovação de calendário anual (prática iniciada somente em 2013). Apenas 1\% das resoluções foi considerada como ligada ao tema "gestão democrática"; são resoluções sobre as eleições de diretoras nas unidades escolares na educação infantil, que se iniciou em 2011. Os dados mostram que o COMERV gastou muito tempo em sua função normativa. Se sua função propositiva e mobilizadora fosse mais efetiva, o COMERV alcançaria resultados mais significativos quanto às questões sociais e políticas para a comunidade local.

Observa-se que o caráter técnico e burocrático está muito presente na atuação do COMERV, como mostra o gráfico a seguir, tendo em vista a prioridade que tem sido dedicada à regularização de documentação sobre o funcionamento das escolas e sobre aprovação de matrizes curriculares e regimentos escolares. É possível considerar que as resoluções 
que tratam da vida escolar de alunos relacionam-se também à qualidade da educação, já que se destinam a garantir isonomia e igualdade de condições. A análise dos dados revela que deveria haver mais ações voltadas para melhoria da qualidade do ensino público municipal. O gráfico abaixo quantifica o conteúdo.

Gráfico 1 - Atuação do COMERV por meio de Resoluções

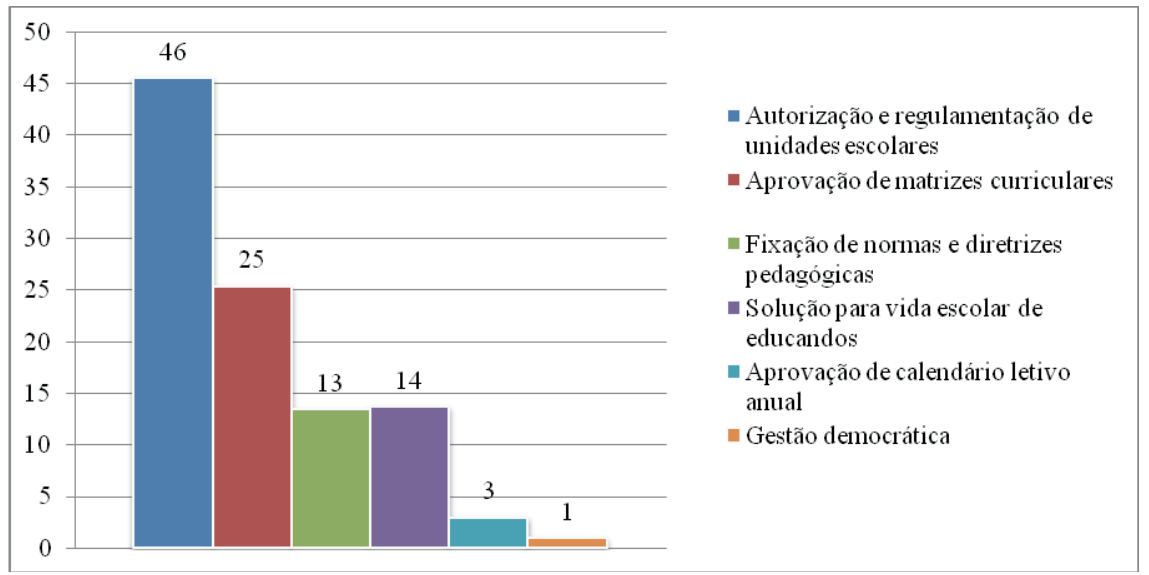

Fonte: elaborado pelas autoras a partir das Resoluções do COMERV - 1997 a 2016.

Para Mendonça (2000, p. 290), “a maneira cartorial como são constituídos alguns colegiados tem levado ao seu funcionamento inadequado". Romper com a função cartorial significa dizer que sua função vai além das funções burocráticas, ou seja, dentro da gestão democrática, intensificar sua função de mobilização social e propositiva.

As resoluções mais significativas quanto à qualidade da educação e selecionadas para discussão durante a investigação se encontram no Quadro 2. 
Quadro 2 - Legislação Municipal

\begin{tabular}{|ll|}
\hline Resolução & Assunto \\
\hline 009/Rio Verde, 2010. & $\begin{array}{l}\text { Condiçães de acesso à escola por crianças com necessidades } \\
\text { especiais. }\end{array}$ \\
\hline 002/ Rio Verde, 2011. & $\begin{array}{l}\text { Normatização e fixação de diretrizes para Educação Infantil do } \\
\text { Sistema Municipal de Ensino. }\end{array}$ \\
\hline $004 /$ Rio Verde, 2011. & Eleição para diretor na Educação Infantil. \\
\hline
\end{tabular}

Fonte: Elaborado pelas autoras a partir das Resoluções do COMERV.

A Resolução 009 (RIO VERDE, 2010), que dispõe sobre "elementos da qualidade da educação que fixa normas complementares para o atendimento educacional especializado na rede municipal de ensino na modalidade especial", busca caminhar para a qualidade social da educação, pois referenda a dignidade da pessoa. A resolução trata das condições de acesso à educação por crianças com necessidades especiais e, assim, prevê questões relacionadas à estrutura e organização do espaço escolar e à contratação de recursos humanos para dar atendimento a esses alunos, como se vê a seguir:

Res.009 - Art. 23 - Ao organizar a educação especial na perspectiva da educação inclusiva, caberá à rede pública municipal de educação disponibilizar servidores para as funções de instrutor/intérprete de Libras, guia-intérprete e outros que atuam no apoio, bem como, professor de apoio pedagógico ou cuidador dos alunos com necessidades de apoio nas atividades de higiene, alimentação, locomoção, entre outras que exijam auxílio constante no cotidiano escolar (RIO VERDE, 2010).

Portanto, não basta que essas condições estejam previstas em documentos oficiais. É preciso, de fato, garantir a qualidade da educação nas condições de acesso e permanência desses alunos na escola pelos critérios de infraestrutura, vagas próximas às residências dos alunos, 
conteúdos que visam à formação do indivíduo na sua totalidade, valorização do profissional da educação, recursos reais de financiamento da educação, dentre outros elementos necessários a garantir o mínimo de dignidade no processo da inclusão. Desta forma, o COMERV aponta para o que é uma educação de qualidade na sua totalidade.

A Resolução nº 02/2011 (RIO VERDE, 2011a), que dispõe sobre a normatização e fixação de diretrizes para a Educação Infantil no Sistema Municipal de Ensino de Rio Verde, está em conformidade com a Resolução Federal nº 0517/ 2009, que prevê as Diretrizes Curriculares Nacionais para Educação Infantil. Agindo em obediência à lei Federal, essa resolução descreve a idade de acesso na modalidade pré-escola e, dentre outros elementos, os profissionais que poderão atuar na educação infantil. Ressalta-se que o teor da Resolução Federal (BRASIL, 2009) busca a qualidade na educação infantil de forma idealizada, como se todos fossem iguais.

O Art. 16 da referida Resolução municipal aponta para a qualidade da Educação Infantil, como se lê: "O profissional do magistério público para atuar na Educação Infantil deverá ser formado em curso de licenciatura plena em pedagogia ou normal superior de nível médio: técnico de magistério, normal ou equivalente" (RIO VERDE, 2011a). Com essa resolução, a comunidade local espera que todas as crianças de 0 a 5 anos tenham acesso à aprendizagem de qualidade, com profissionais habilitados para o ensino formal. Para além da visão assistencialista que ainda subsiste na educação infantil brasileira, Lima (2010) ressalta a importância de esse encaminhamento dar-se na busca da qualidade da educação.

$\mathrm{Na}$ mesma resolução, o parágrafo $2^{\circ}$ dispõe que não se pode ultrapassar 30\% do quantitativo da relação criança/professor e que, caso seja alcançado esse quantitativo, deve ocorrer novo agrupamento na préescola e na creche, o que implica na contratação de mais servidores de apoio e higienização. Sabe-se que existe um distanciamento entre a letra da lei e a realidade educacional. Dois pontos que necessitam destaque nesse contexto são: a) a resolução trata da qualidade da educação e, por isso, há necessidade de fiscalização do COMERV para exigir da SME ajustes nesse agrupamento para que não ocorra número bem maior do 
que o previsto no documento legal; b) a intensificação da importância de professores especializados na modulação da educação infantil e a participação efetiva que garanta a coletividade na qualidade educacional.

Outro fator importante para a qualidade da educação é a gestão democrática presente na Resolução 004 (RIO VERDE, 2011b), que designou, pela primeira vez, a realização de eleição para diretoras na educação infantil de Rio Verde. Essa resolução fez com que cessassem os apadrinhamentos políticos, dando condições de participação daqueles que pretendessem disputar o processo eleitoral. Nessas condições, o sentimento de igualdade e de isonomia no corpo docente revigora a esperança de que, em meio a um sistema neoliberal, ainda seja possível encontrar ações voltadas para a democracia. O Art. 206 da Constituição Federal, reiterado no Art. $3^{\circ}$ da Lei de Diretrizes e Bases da Educação Nacional (9.394/96), menciona a "gestão democrática do ensino público, na forma desta Lei e da legislação dos sistemas de ensino" (inciso VIII do art. $3^{\circ}$ da LDB). O Art. 14 da LDB trata especificamente dessa questão, determinando que os sistemas de ensino definam as normas da gestão democrática do ensino público na Educação Básica de acordo com as suas peculiaridades, conforme os seguintes princípios: I - participação dos profissionais da Educação na elaboração do projeto pedagógico da escola; II - participação das comunidades escolar e local em conselhos escolares ou equivalentes.

Diante desses dados é possível afirmar que trabalhar a gestão democrática dentro do princípio democrático social é: compreender que o papel dos conselheiros como mediadores diante das tomadas de decisões quanto às políticas públicas educacionais; encontrar um meio termo entre a vontade do povo e a vontade política para que haja uma ponderação, um equilíbrio entre a vontade do povo e a vontade governamental.

Dentre suas funções, normativa e deliberativa, o COMERV, nas Resoluções de 1997 a 2016, discutiu vários assuntos que mostram a preocupação com a qualidade da educação, como autorização e regulamentação, aprovação de matrizes curriculares, fixação de normas, a solução para a vida escolar, a aprovação do calendário anual e a eleição democrática. 
Por outro lado, o COMERV teve muito tempo gasto em sua função normativa, o que confirma a fala de Alves (2011, p. 44):

Em suas funções, vários CMEs ainda não conseguiram romper as práticas cartoriais confundindo-se, muitas vezes, como departamentos das Secretarias Municipais de Educação. Isto se deve, além da herança histórica, ao modelo de desconcentração gerencial implantada na reforma do Estado brasileiro na década de 1990.

Nesse sentido, se sua função propositiva e mobilizadora fosse mais efetiva, o COMERV alcançaria resultados mais significativos quanto às questões sociais e políticas para a comunidade local. As metas previstas no PME, por exemplo, devem fazer pauta das ações do COMERV, pois exigiriam ações de caráter propositivo e mobilizador para orientar a sociedade sobre os compromissos firmados pelo poder público e, junto com ela, cobrar pelo seu cumprimento.

Em um país em que prevalece tamanha desigualdade social, estado de pobreza e miséria como no Brasil, pode-se afirmar que o Conselho tem a possibilidade de ser uma instituição que pode contribuir para mudar o rumo das políticas públicas educacionais municipais, com participação social efetiva, numa concepção de que a democracia é processual e que em alguns momentos ela avança e em outro ela retroage (LIMA, 2010). Os conselhos municipais, mesmo sendo órgãos governamentais, podem, sim, ter sua identidade e adquirir respeito por meio dela, posicionandose com autenticidade. Para isso, seria necessário apropriar-se de conhecimentos que os fizessem perceber a alienação que os rodeiam. O mundo do capital trabalha para isso, ou seja, alienar os grupos de classe e, consequentemente, os cidadãos para que tenham a impressão de que vivemos em um país que respeita a opinião pública na sua totalidade.

Enquanto os interesses educacionais não beneficiarem o povo, que verdadeiramente necessita deles para melhorar sua situação na sociedade, a educação não avançará em termos de melhoria qualitativa, pois "as políticas públicas para a educação nacional não visam outro alvo senão 
interesses políticos que buscam evitar o povo prosperar, e prejudicar o poder" (SAVIANI, 1992).

A qualidade socialmente referenciada da educação deveria ser a bandeira dos conselhos municipais de educação. Em seu papel propositivo, deveria intensificar a mobilização social para que, ao menos o governo local, se sentisse pressionado e reagisse a favor do povo, a favor da aprendizagem de qualidade. Um instrumento importante é o Plano Municipal de Educação. O conselho sendo um dos atores na sua elaboração e agora na sua implementação e monitoramento, precisa ter como aliado a sociedade local para que de fato se lute pela qualidade da educação.

\section{Considerações finais}

Diante do exposto, é preciso admitir que a democracia no contexto do COMERV deve ser ampliada para que a participação ativa e consciente dos representantes seja a forma de acesso da sociedade nas tomadas de decisões das políticas públicas educacionais locais. Nesse sentido, deve colaborar na promoção de espaços de discussões com a sociedade e comunidade escolar sobre questões com grande impacto social por meio de audiências públicas, fóruns, reuniões em loco (escolas), para que ouça os anseios de toda população. Acreditar numa educação socialmente referenciada significa acreditar numa educação acima de média quantitativista e perceber que a melhoria é o oferecimento de oportunidades iguais para todos no processo educativo.

A pesquisa revelou que a atividade burocrática na execução da função deliberativa do COMERV é preponderante sobre as outras funções, sendo que a função mobilizadora e propositiva é exercida de maneira tímida. Dessa forma, o COMERV está timidamente no caminho da qualidade social da educação, precisando observar os anseios sociais da comunidade e se adequar ao contexto social, cultural e político do país e movimentar a participação da gestão democrática. O COMERV mantém bom relacionamento com poder local no seu papel de mediador. Esse fator é importante 
para encontrar o meio termo sobre determinadas situações. Nota-se, também, que os membros do Conselho se mostram dispostos a atualizar seus conhecimentos e demonstram interesse nas críticas construtivas.

A análise das resoluções permite perceber mais pontualmente a tímida atuação do COMERV frente às políticas educacionais. É preciso ampliar a ação do COMERV em direção à qualidade da educação socialmente referenciada. Para tanto, é preciso que a sociedade em geral entenda que o COMERV, apesar de ser uma instância institucionalizada, pode também representar os setores populares e que deve servir de espaço de expressão autônoma das necessidades sociais locais por meio da participação da sociedade.

Compreende-se que o movimento investigativo está longe de se esgotar, pois o mesmo deve acontecer de forma processual e contextualizada. Nesse sentido, busca-se fortalecer as reflexões que permitam um maior entendimento da complexidade que envolve a qualidade da educação na atuação do COMERV, principalmente nesse momento histórico, em que deve haver monitoramento do PME.

\section{Referências}

ALVES, E. F. Conselhos Municipais de educação em Goiás: historicidade, movimentos e possibilidades. 209 fls. Dissertação (Mestrado em educação) — Universidade Federal de Goiás, Goiânia, 2011.

BORDIGNON, G. Gestão da Educação no Município: Sistema, Conselho e Plano. Instituto Paulo Freire: São Paulo, 2009.

BRASIL. Ministério da Educação - Secretaria de Educação Básica. Programa Nacional de Fortalecimento dos Conselhos Escolares. Conselho Escolar: uma estratégia de gestão democrática da educação pública. Brasília: MEC, 2004.

BRASIL. Ministério da Educação. Resolução n. 5 17/dez/2009. Fixa as Diretrizes Curriculares Nacionais para a Educação Infantil. Diário Oficial da União. Seção 1, 9 dez. 2009. 
BRASIL. Ministério da Educação. Diretrizes Curriculares Nacionais Gerais da Educação Básica. Secretaria de Educação Básica. Diretoria de Currículos e Educação Integral. Brasília: MEC/SEB/DICEI, 2013.

CASTRO, C. de M.; CARNOY, M. Como anda a reforma da educação na América Latina? Rio de Janeiro: Fundação Getúlio Vargas, 1997.

CASTRO, M. H. G. de. A Educação para o século XXI: o desafio da qualidade. Brasília: Instituto Nacional de Estudos e Pesquisas Educacionais, 1999.

CONAE. Documento final da Conferência Nacional de Educação 2014. O PNE na articulação do sistema nacional de educação: participação popular, cooperação federativa e regime de colaboração. Brasília, DF: MEC, 2015. Disponível em: <http://www.conae.mec.gov.br〉. Acesso em: 07 out. 2015.

CURY, C. R. J. Os Conselhos de Educação e a Gestão dos Sistemas. In: FERREIRA, N. S. C.; AGUIAR, M. A. S. (Orgs.). Gestão da Educação: impasses, perspectivas e compromissos. 5. ed. São Paulo: Cortez, 2011.

GAMBOA, S. S. Pesquisa em educação: métodos e epistemologia. Chapecó: Argos, 2007. HADDAD, F. Plano de Desenvolvimento da Educação: razões, princípios e programas. Brasília: Instituto Nacional de Estudos e Pesquisas Educacionais Anísio Teixeira, 2008.

LIMA, A. B. de. Conselhos Municipais na Educação: Perspectivas de Democratização da Política Educacional Municipal. Dissertação (Mestrado em Educação) Pontifícia Universidade Católica de São Paulo/SP, 2001.

LIMA, A. B. de. Conselhos de educação, movimentos sociais e controle social. Educação em Perspectiva, Viçosa, v. 1, n. 1, jan./jun. 2010. Disponível em: <http:// www.seer.ufv.br/seer/educacaoemperspectiva/index.php/ppgeufv/article/ view/9 >. Acesso em: 14 fev. 2017.

LIMA, A. B. de. Qualidade na (da) educação: Aproximações e retenções sobre o tema. In: LIMA, A.B de. (Org.). Qualidade da Educação Superior: O Programa Reuni. Jundiaí: Paco Editorial, 2014. 
MENDONÇA, E. F. A regra e o jogo: democracia e patrimonialismo na educação brasileira. 232 p. Tese (Doutorado em Educação) - Universidade Estadual de Campinas, Campinas, 2000.

MOTTA, F. C. P. Administração e Participação: Reflexões para a Educação. Revista da Faculdade de Educação, São Paulo, n. 2, 1984.

RIO VERDE. Prefeitura Municipal. Decreto n. 3.496, 14 de maio de 1997. Dispõe sobre Lei de criação do Conselho Municipal de Educação. Rio Verde-GO: Poder Executivo, 1997a.

RIO VERDE. Prefeitura Municipal. Decreto n. 3.544, de 11 de agosto de 1997. Dispõe sobre a alteração da Lei de criação do Conselho Municipal de Educação de n. 3.496 de 14 de maio de 1997. Rio Verde-GO: Poder Executivo, 1997b.

RIO VERDE. Prefeitura Municipal. Decreto n. 847, 14 de abril de 2014. Regimento Interno Conselho Municipal de Educação de Rio Verde. Rio Verde-GO: Poder Executivo, 2014. Disponível em: 〈http://web-comerv.cloudapp.net/>. Acesso em: 20 de mar. 2016.

RIO VERDE. Conselho Municipal de Educação. Resolução 009 de 28 de abril de 2010. Fixa normas complementares para o atendimento educacional especializado na rede pública municipal, modalidade Educação Especial. Rio Verde-GO: COMERV, 2010 Disponível em: <http://web-comerv.cloudapp.net/>. Acesso em: 18 fev. 2016.

RIO VERDE. Conselho Municipal de Educação. Resolução 002 de 27 de abril de 2011. Normatiza e fixa diretrizes para o funcionamento da Educação Infantil no Sistema Municipal de Ensino e dá outras providências. Rio Verde-GO: COMER, 2011a. Disponível em: <http://web-comerv.cloudapp.net/. Acesso em: 18 fev. 2016.

RIO VERDE. Conselho Municipal de Educação. Resolução 004 de 18 de maio de 2011. Dispõe sobre a idade de acesso à Educação Infantil e ao Ensino Fundamental no Sistema Municipal de Ensino e dá outras providências. Rio Verde-GO: COMERV, 2011b Disponível em: <http://web-comerv.cloudapp.net/>. Acesso em: 18 fev. 2016. 
SAVIANI, D. Pedagogia Histórico-Crítica: Primeiras aproximações. 3. ed. Campinas: Cortez, 1992.

TEIXEIRA, L. H. G. Conselhos Municipais de Educação: autonomia e democratização do ensino. Cadernos de Pesquisa, v. 34, n. 123, p. 691-708, set./dez. 2004.

Recebido: 30/04/2018

Received: 04/30/2018

Recibido: 30/04/2018

Aprovado: 20/05/2018 Approved: 05/20/2018 Aprobado: 20/05/2018 